\title{
A Nitric Oxide-like Factor Mediates Nonadrenergic-Noncholinergic Neurogenic Relaxation of Penile Corpus Cavernosum Smooth Muscle
}

Noel Kim, Kazem M. Azadzoi, Irwin Goldstein, and Iñigo Saenz de Tejada

Department of Urology, Boston University Medical Center, Boston, Massachusetts 02118

\begin{abstract}
This study was initiated to characterize nonadrenergic-noncholinergic (NANC) inhibitory neurotransmission in penile corpus cavernosum. Using organ baths, isometric tension measurements were made in strips of human and rabbit corpus cavernosum. In examining endothelium-mediated responses, cumulative additions of exogenous acetylcholine elicited dose-dependent relaxations which were significantly reduced or completely inhibited in tissues treated with $\mathbf{N}^{\mathbf{G}}$-monomethyl L-arginine (L-NMMA; an inhibitor of nitric oxide synthesis), oxyhemoglobin (a nitric oxide scavenger), or methylene blue (a guanylate cyclase blocker). Tissues exposed to hypoxic conditions $\left(\mathrm{PO}_{2}=5-10 \mathrm{mmHg}\right)$ also did not respond to exogenous acetylcholine. Mechanical removal of the endothelium in human corporal strips or in situ treatment of rabbit corpora with detergent blocked the relaxation to acetylcholine. Transmural electrical stimulation of corporal tissue strips denuded of functional endothelium, in the presence of adrenergic blockade with bretylium and muscarinic receptor blockade with atropine, caused frequency-dependent relaxation. This neurogenic relaxation was reduced or prevented by L-NMMA, oxyhemoglobin, methylene blue, and hypoxia. The effects of $L$-NMMA were reversed by $L$-arginine and the effects of hypoxia were readily reversed by normoxic conditions. Authentic, exogenous nitric oxide relaxed corporal strips which were contracted with adrenergic agonists and this effect was significantly inhibited by oxyhemoglobin. It is concluded that $(a)$ endothelium-mediated responses of corpus cavernosum smooth muscle are mediated by a diffusible nitric oxide-like substance; (b) NANC neurogenic inhibitory responses do not require functional endothelium, and (c) nitric oxide, or a closely related substance, may act as an inhibitory neurotransmitter in penile corpus cavernosum smooth muscle. (J. Clin. Invest. 1991. 88:112-118.) Key words: EDRF • monomethyl arginine • oxyhemoglobin • hypoxia $\bullet$ methylene blue
\end{abstract}

\section{Introduction}

Erection follows the relaxation of penile corpus cavernosum smooth muscle which is initiated by sacral parasympathetic stimulation. Locally, relaxation is mediated by a nonadrener-

Address correspondence to Iñigo Saenz de Tejada, M.D., 720 Harrison Ave., P 606, Dept. of Urology, Boston University School of Medicine, Boston, MA 02118.

Received for publication 21 September 1990 and in revised form 13 February 1991

J. Clin. Invest.

(c) The American Society for Clinical Investigation, Inc. $0021-9738 / 91 / 07 / 0112 / 07 \quad \$ 2.00$

Volume 88, July 1991, 112-118 gic-noncholinergic (NANC) ${ }^{1}$ neurotransmitter(s) (1) and by the endothelium via the release of an endothelium-derived relaxing factor (EDRF) $(1,2)$. In vitro, transmural stimulation of isolated corpus cavernosum strips elicits a neurogenic, frequency-dependent relaxation that is completely blocked by the neurotoxin tetrodotoxin but is resistant to adrenergic and cholinergic blockers (1). Thus, it is characterized as a NANC-mediated response. The chemical nature of the NANC neurotransmitter in penile smooth muscle is unknown. Recent studies suggest that nitric oxide is a neurotransmitter in both central and peripheral nervous systems (3-8). Furthermore, electrical field stimulation of rabbit corporal strips causes the release of nitric oxide and accumulation of CGMP in corporal tissue (3). However, it has not been determined if the source of nitric oxide is the NANC neuron itself or the endothelium stimulated by these nerves.

The aim of this study was to characterize NANC neurotransmission in penile smooth muscle. It has been shown that nitric oxide is synthesized and released by the endothelium of blood vessels and accounts for the activity of $\operatorname{EDRF}(1,2,9$, 10). The synthesis, release, or effects of nitric oxide can be inhibited with $\mathrm{N}^{\mathrm{G}}$-monomethyl L-arginine, oxyhemoglobin, hypoxic conditions, or methylene blue $(2,11-14)$. Using these conditions, we have studied human and rabbit corpus cavernosum denuded of functional endothelium and examined NANC-mediated relaxation of corporal smooth muscle.

\section{Methods}

\section{Materials}

$\mathrm{N}^{\mathrm{G}}$-Monomethyl L-arginine acetate (L-NMMA) and 3-[(3-cholamidopropyl)-dimethylammonio]-1-propane sulfonate (CHAPS) were purchased from Calbiochem-Behring Corp., La Jolla, CA. Bretylium tosylate (2-bromo- $N$-ethyl- $N, N$-dimethylbenzenemethanaminium 4methylbenzenesulfonate) was obtained from American Critical Care, McGraw Park, IL. All gas mixtures were obtained through MedicalTechnical Gases, Inc., Medford, MA. All other drugs and reagents were purchased from commercially available sources.

Buffer

Physiological salt solution (PSS): $118.3 \mathrm{mM} \mathrm{NaCl}, 25.0 \mathrm{mM} \mathrm{NaHCO}_{3}$, $11.1 \mathrm{mM}$ D-glucose, $4.7 \mathrm{mM} \mathrm{KCl}, 2.5 \mathrm{mM} \mathrm{CaCl}_{2}, 1.2 \mathrm{mM} \mathrm{KH}_{2} \mathrm{PO}_{4}$, $0.6 \mathrm{mM} \mathrm{MgSO}_{4}, 0.026 \mathrm{mM} \mathrm{CaNa}_{2}$ EDTA.

\section{Nitric oxide dose response}

Test tubes were filled with distilled, deionized water and capped with rubber stoppers. The water was degassed under vacuum at room temperature for $30 \mathrm{~min}$. The tubes were then placed on ice and bubbled

1. Abbreviations used in this paper: ACh, acetylcholine; CHAPS, 3-[(3cholamidopropyl)-dimethylammonio]-1-propane sulfonate; EDRF, endothelium-derived relaxing factor; L-NMMA, $N^{G}$-monomethyl Larginine; NANC, nonadrenergic-noncholinergic; PSS, physiological salt solution; TES, transmural electrical stimulation. 
with pure $\mathrm{N}_{2}$ gas for an additional $20 \mathrm{~min}$ via long cannulas (18 gauge, 3 in) inserted through the rubber stoppers. Additional, shorter needles were inserted through the rubber stoppers to relieve pressure and to enable gas flow. While still on ice, one of the tubes was bubbled with NO gas for $10 \mathrm{~min}$ to yield a saturated solution of nitric oxide $\left(\sim 10^{-3}\right.$ M). Serial dilutions were performed by transferring aliquots between capped tubes with a syringe. Stock solutions were used within $15 \mathrm{~min}$ of preparation and discarded after each use.

\section{Preparation of oxyhemoglobin}

Hemoglobin A was isolated from human donors using an abbreviated version of a protocol described elsewhere (15). Blood (30 ml) was collected in $3 \mathrm{ml}$ of $3.8 \%$ citrate and centrifuged at $180 \mathrm{~g}$ for $30 \mathrm{~min}$. All subsequent procedures were carried out at $4^{\circ} \mathrm{C}$. Packed red blood cells were transferred into a separate container and lysed by suspension in $10 \mathrm{vol}$ of $5 \mathrm{mM}$ Tris $(\mathrm{pH} \mathrm{8.1)}$. The hemolysate was centrifuged at $100,000 \mathrm{~g}$ for $30 \mathrm{~min}$ to separate out membrane components. The resulting supernatant was passed through a column of microgranular DE52 (Whatman Inc., Clifton, NJ) which was equilibrated with 50 $\mathrm{mM}$ Tris, pH 8.1. The sample was eluted with $75 \mathrm{mM} \mathrm{NaCl}, 25 \mathrm{mM}$ Tris, $\mathrm{pH} 7.0$. Hemoglobin preparations were stored at $-80^{\circ} \mathrm{C}$ until use. The concentration of oxyhemoglobin was determined spectrophotometrically using the millimolar extinction coefficient $\epsilon_{415} 125$ (16).

\section{Tissue procurement}

Human. Human corpus cavernosum tissue was obtained from nondiabetic patients with organic impotence receiving penile prosthesis implants. This protocol was approved by the Institutional Review Board for Human Studies at the Boston University Medical Center. All tissue donors issued informed consent. Tissues were transported to the laboratory in ice-cold PSS for immediate study. Strips of human corpus cavernosum $(3 \times 3 \times 7 \mathrm{~mm})$ were cut from the corporal biopsy and mounted in organ baths (see below).

Rabbit. Male New Zealand White rabbits (3.0-3.5 kg) were anesthetized with sodium pentobarbital and exsanguinated, as previously described (17). Rabbit penises were surgically removed en bloc, with care being taken to keep the tunica albuginea intact. The corpus spongiosum and urethra were excised. The corpus cavernosum tissue was carefully dissected free from the surrounding tunica albuginea and mounted in organ baths (see below). This protocol was approved by the Animal Care Committee at the Boston University Medical Center.

\section{Disruption of endothelium}

Human. Strips of human corpus cavernosum were rubbed between the thumb and index finger for $\sim 20 \mathrm{~s}(1)$. After rinsing in chilled PSS, tissue strips were gently rolled across a dry paper towel to generate shear forces across the endothelial surfaces of the lacunar spaces. This method was deemed to be effective in the removal of endothelium by the nearly complete absence of staining for factor VIII (an endothelium tissue-specific marker [18]) when compared with tissues which were not rubbed (see Fig. 3). Corporal strips were placed in organ baths and subjected to cumulative additions of acetylcholine $\left(\mathrm{ACh} ; 10^{-9}-10^{-4} \mathrm{M}\right)$ as a functional test of endothelial integrity. Rubbed tissues did not respond to acetylcholine (Fig. $1 A,-E n d o$ ).

Rabbit. The endothelium lining the lacunar spaces of rabbit corpus cavernosum was disrupted and/or removed by detergent treatment using a modification of a protocol for blood vessels, described elsewhere (19). The intact, isolated penis was placed in a tray containing chilled PSS. A 21-gauge minicatheter was inserted into each (left and right) corporal body at the proximal end of the crus of the penis. A third minicatheter was inserted into the distal end, below the glans penis, where the right and left corpora communicate. While the distal and one proximal minicatheter was clamped, $3 \mathrm{ml}$ of $0.5 \%$ CHAPS ( $\mathrm{wt} / \mathrm{vol}$ ) in a solution of normal saline was infused into the remaining proximal catheter. Leakage of the CHAPS solution through venous drainage was minimal. After a short interval $(\sim 20 \mathrm{~s})$, the clamped minicatheters were opened and the preparation was extensively washed by infusion of
PSS. This procedure was repeated for the proximal catheter on the opposite side. The corpora cavernosa were then removed and tested for endothelial integrity, as described above. Of the tissues treated with CHAPS, $53 \%$ did not relax or relaxed poorly ( $<15 \%$ of maximal relaxation) to $\mathrm{ACh}$ and were considered to be functionally denuded of endothelium. These tissues were used for this study.

\section{Immunohistochemistry}

Human corpus cavernosum tissue samples were fixed in $4 \%$ paraformaldehyde, embedded in paraffin, and sectioned. The anti-factor VIII peroxidase antiperoxidase technique was used to detect factor VIII antigen, as previously described (20).

\section{Organ bath experiments}

Strips of human or rabbit corpus cavernosum were mounted with surgical suture to a fixed metal loop from below and a metal wire from above, connected to a force transducer (Model FT03; Grass Instruments, Quincy, MA). The preparation was then immersed in 25-ml baths maintained at $37^{\circ} \mathrm{C}$ and containing PSS (aerated with $5 \% \mathrm{CO}_{2}$, $95 \%$ air to attain $\mathrm{pH} 7.4$ ). As previously described (17), optimal isometric tension was achieved by gradual, incremental stretching. The tissue was periodically tested by contracting with either $10^{-6} \mathrm{M}$ phenylephrine $((R)$-3-hydroxy- $\alpha$-[(methylamino)methyl]-benzenemethanol hydrochloride) or $10^{-6} \mathrm{M}$ norepinephrine (4-(2-amino-1-hydroxyethyl)1,2-benzenediol). Tissues were considered to have reached optimal isometric tension when two successive contractions were within $10 \%$ of each other. After this determination, tissues were relaxed maximally with $10^{-4} \mathrm{M}$ sodium nitroprusside (sodium nitrosylpentacyanoferrate (III)) to determine baseline. After thorough washout, the tissues were contracted with either norepinephrine or phenylephrine and subjected to cumulative additions of acetylcholine $\left(10^{-9}-10^{-4} \mathrm{M}\right)$ or transmural electrical stimulation (TES). All experiments were performed in the presence of $3 \times 10^{-6} \mathrm{M}$ indomethacin (1-(4-chlorobenzoyl)-5-methoxy-2-methyl-1 $\mathrm{H}$-indole-3-acetic acid) and $10^{-5} \mathrm{M}$ bretylium. Tissues receiving electrical stimulation were also treated with $10^{-7} \mathrm{M}$ atropine ( $\alpha$-(hydroxymethyl)benzeneacetic acid 8-methyl-8-azabicyclo[3.2.1]oct-3-yl ester sulfate) as well as indomethacin and bretylium. TES was accomplished by means of two platinum plate electrodes, positioned on either side of the tissue, and a current amplifier in series with a S8800 stimulator (Grass Instruments, Quincy, MA). Each stimulation lasted $20 \mathrm{~s}$ at the indicated frequencies $(0.5-40 \mathrm{~Hz})$ and the following constant parameters: $10 \mathrm{~V}, 0.5 \mathrm{~ms}$ pulse duration. Treated tissues were incubated with either $3 \times 10^{-4} \mathrm{M}$ L-NMMA, $10^{-4} \mathrm{M}$ methylene blue (3,7-bis(dimethylamino)phenothiazin-5-ium chloride), or hypoxic conditions $\left(95 \% \mathrm{~N}_{2}, 5 \% \mathrm{CO}_{2}\right)$ for $20 \mathrm{~min}$ before the responses to acetylcholine or TES were performed. For oxyhemoglobin $\left(3 \times 10^{-5} \mathrm{M}\right)$ treated tissues, responses to acetylcholine or TES were performed as soon as a stable contraction was attained following the addition of oxyhemoglobin.

\section{Calculations}

Relaxations within a dose response curve were measured from a common reference line denoting the amount of stable tone which the tissue achieved before stimulation ( $0 \%$ relaxation). The perpendicular vertical distance between this reference line and the largest downward deflection in the tracing at any given dose was recorded as the response at that dose. All responses are expressed as percentage of maximal relaxation which was induced by the addition of $1 \mathrm{mM}$ sodium nitroprusside or $0.1 \mathrm{mM}$ papaverine (1-[(3,4-dimethoxyphenyl)methyl]-6,7-dimethoxyisoquinoline hydrochloride) at the end of the experiment. Data are expressed as mean \pm SE for $\boldsymbol{n}$ different individuals. For $\mathrm{EC}_{50}$ values, Hill plots were constructed by plotting $\log [\mathrm{ACh}]$ versus log $\left[R /\left(R_{\max }-R\right)\right]$, where $R=$ percent relaxation and $R_{\max }=$ percent maximal response. Linear regression by the method of least squares was used to determine the line of best fit and $\mathrm{EC}_{50}$ values were then taken as the concentration at which $\log \left[R /\left(R_{\max }-R\right)\right]=0$ (i.e., $R=50 \%)$. 

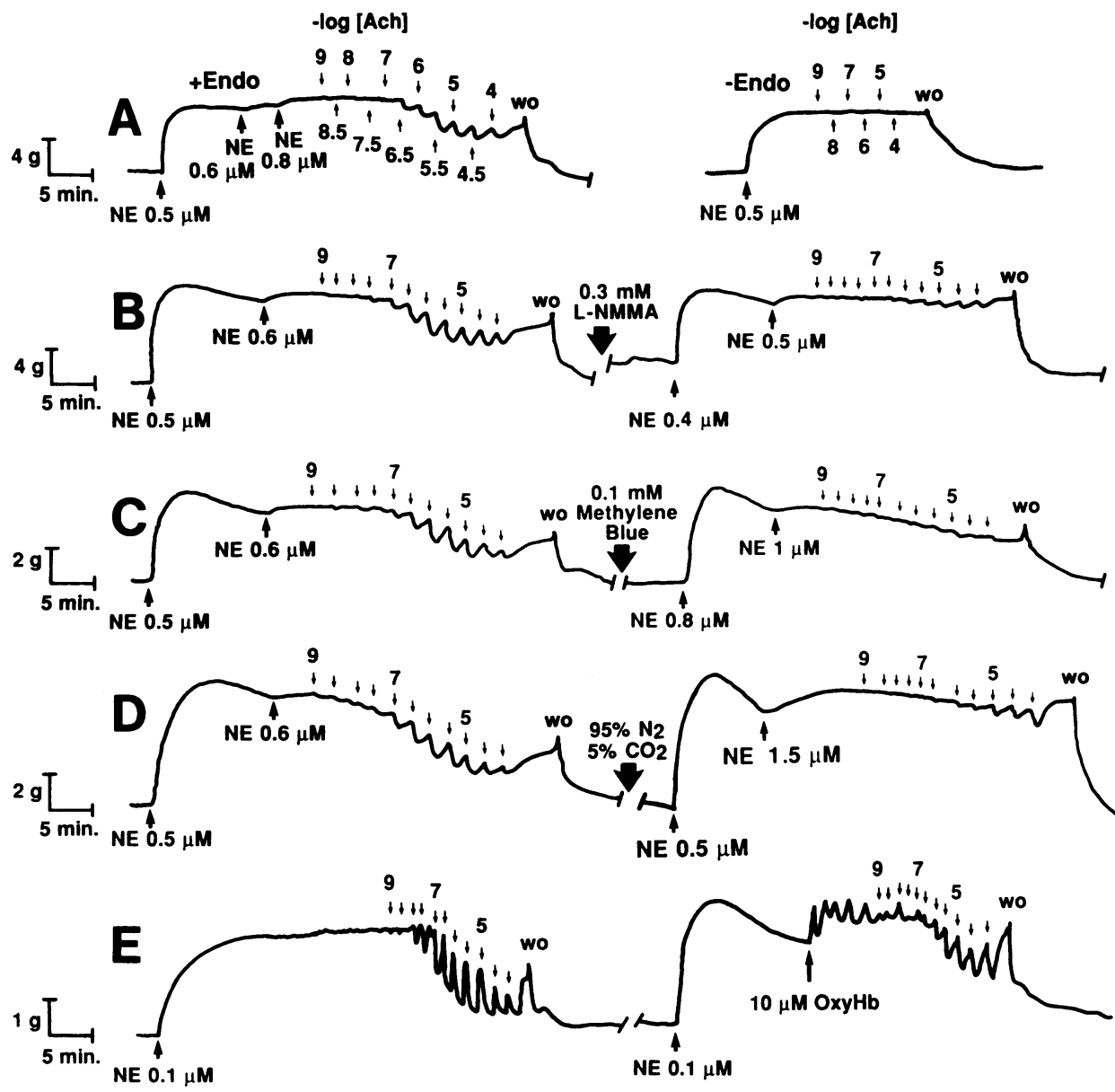

NE $0.5 \mu \mathrm{M}$

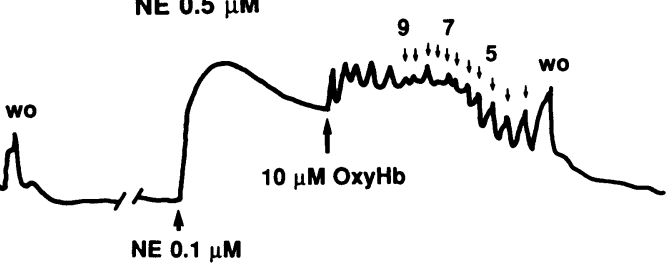

Figure 1. Responses of human corpus cavernosum to acetylcholine. Strips of endothelium intact corporal tissue $(A,+E n d o)$ or tissue devoid of endothelium $(A$, - Endo) were contracted with norepinephrine $(N E)$ and increasing concentrations of $\mathrm{ACh}$ were added in a cumulative fashion. Control ACh dose response curves were performed in other tissues strips $(B-D)$. After several exchanges of fresh buffer, tissues were treated with $0.3 \mathrm{mM}$ L-NMMA $(B), 0.1 \mathrm{mM}$ methylene blue $(C), 95 \% \mathrm{~N}_{2}, 5 \% \mathrm{CO}_{2}$ (hypoxic conditions) $(D)$, or 10 $\mu \mathrm{M}$ oxyhemoglobin $(E)$. Dose responses to acetylcholine were repeated as soon as a stable contraction was obtained $(E)$ or following a 20-min incubation with the appropriate drug $(B-D)$. All protocols were carried out in the presence of $3 \mu \mathrm{M}$ indomethacin. See Fig. 2 for summary data. Exchanges of fresh PSS denoted by wo (washout).

\section{Results}

Responses to acetylcholine. Human and rabbit corpus cavernosum strips contracted with norepinephrine or phenylephrine and treated with increasing concentrations of acetylcholine relaxed maximally at 1-10 $\mu \mathrm{M}$ ACh with $\mathrm{EC}_{50}$ values of $221 \pm 30$ $\mathrm{nM}$ (human) and $69 \pm 15 \mathrm{nM}$ (rabbit). Relaxations to ACh were significantly reduced $\left(E_{50}>10^{-5} \mathrm{M}\right)$ or completely inhibited by 10-30 $\mu \mathrm{M}$ oxyhemoglobin, $0.3 \mathrm{mM}$ L-NMMA, hypoxia $\left(\mathrm{PO}_{2}=5-10 \mathrm{mmHg}\right)$, or $0.1 \mathrm{mM}$ methylene blue in both human (Figs. 1 and $2 H$ ) and rabbit (Fig. $2 R$ ) corpus cavernosum preparations. L-Arginine $(0.3 \mathrm{mM})$, but not its enantiomer, $D-$ arginine $(0.3 \mathrm{mM})$, prevented the inhibitory effects of $\mathrm{L}$ NMMA. Also, the inhibitory effects of hypoxia were reversed with normoxic conditions ( $95 \%$ air, $5 \% \mathrm{CO}_{2}$ ). Rubbing strips of human corpus cavernosum tissue removes the endothelium which lines the lacunar spaces (see Fig. 3). As shown in Fig. $1 \mathrm{~A}$ ( - Endo), these strips of human tissue (as well as rabbit corporal tissue treated in situ with a detergent; data not shown) lost their response to ACh. Authentic, exogenous nitric oxide fully relaxed human and rabbit corpus cavernosum at $10^{-5} \mathrm{M}\left(\mathrm{EC}_{50}\right.$ $=286 \mathrm{nM}$ and $50.2 \mathrm{nM}$, respectively). As shown in Fig. 4, this relaxation was significantly inhibited $\left(E_{50}>10^{-5} \mathrm{M}\right)$ in the presence of $30 \mu \mathrm{M}$ oxyhemoglobin in both human and rabbit corporal tissue.

Neurogenic relaxation. NANC neurogenic responses were studied in human and rabbit corpus cavernosum strips which were denuded of functional endothelium and treated with bretylium (to inhibit adrenergic neurotransmission) and atropine (to block muscarinic $\mathrm{ACh}$ receptors). Mean values of responses to electrical stimulation in the absence of nitric oxide or guanylate cyclase inhibitors are given in Table I. As shown by the responses in Fig. 5 (human) and by the summarized data in Fig.

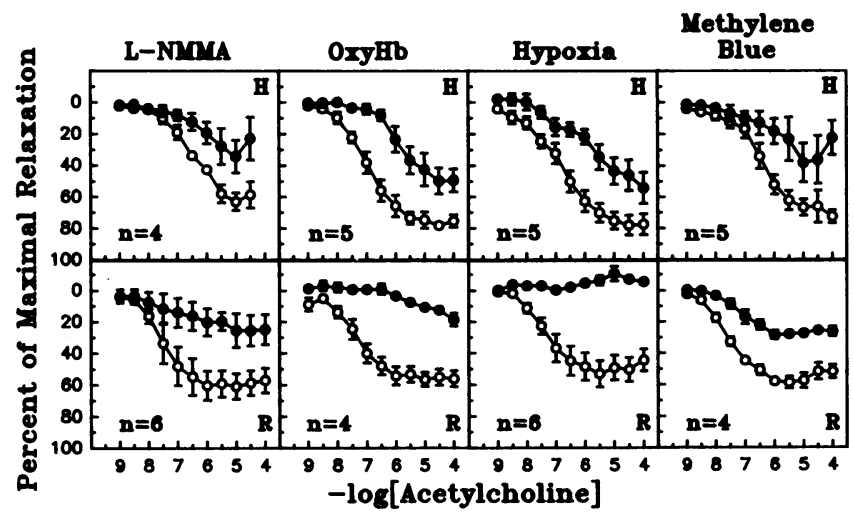

Figure 2. Responses to acetylcholine. Human $(H)$ and rabbit $(R)$ corpus cavernosum tissues were subjected to identical experimental protocols as described in Fig. 1. Control responses (open circles); responses to indicated treatments (solid circles). Parallel time controls (not shown), in which tissues did not receive treatment with inhibitors, exhibited no significant variance in responses over time. 

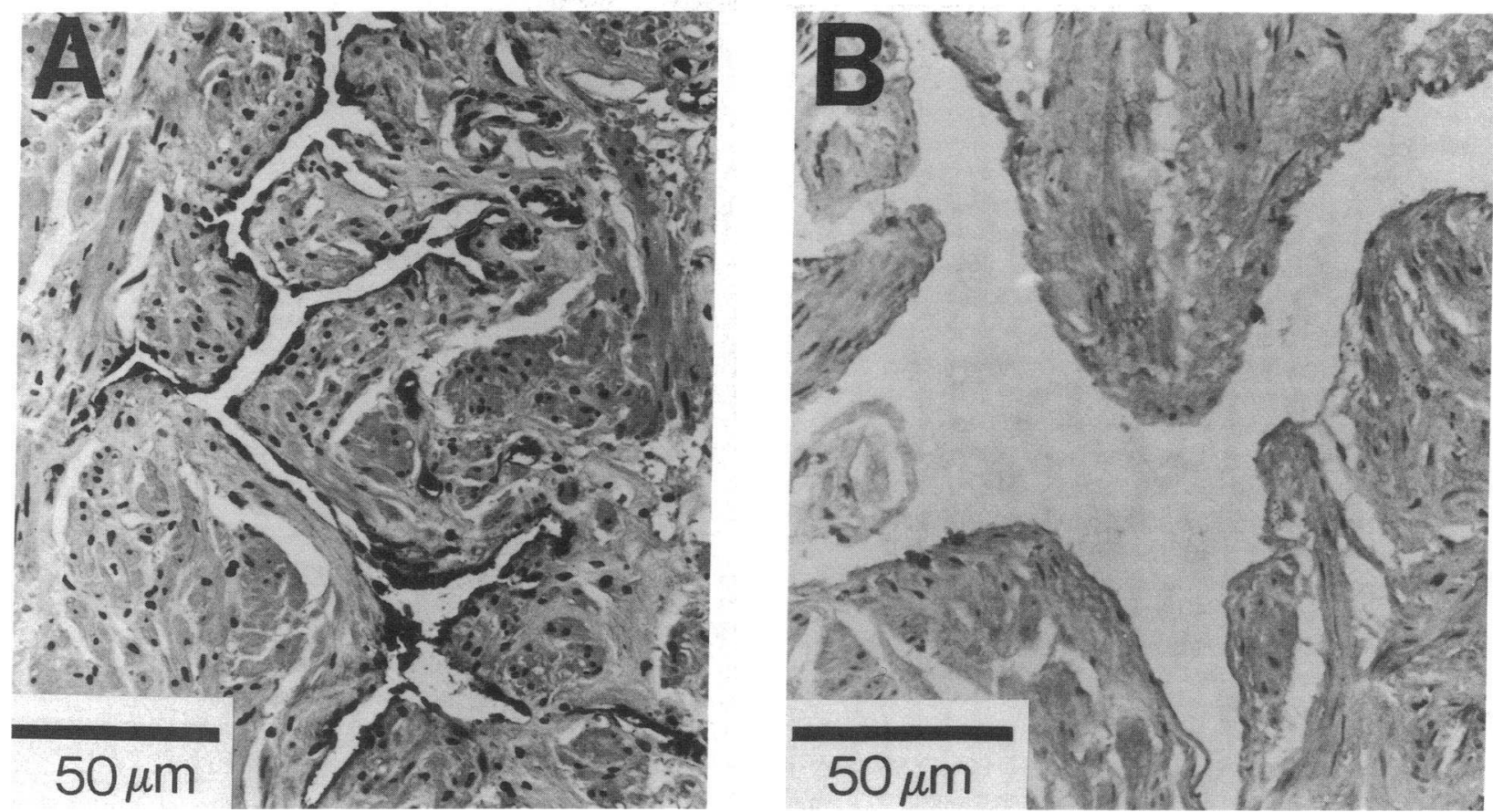

Figure 3. Staining of human corpus cavernosum endothelium by anti-factor VIII antibody utilizing the peroxidase-antiperoxidase technique. The intima of the lacunar spaces stains positively in a control corporal tissue section $(A)$. The periphery of the lacunar spaces is devoid of staining in corporal tissue subjected to mechanical manipulation, demonstrating the removal of the endothelium $(B)$.
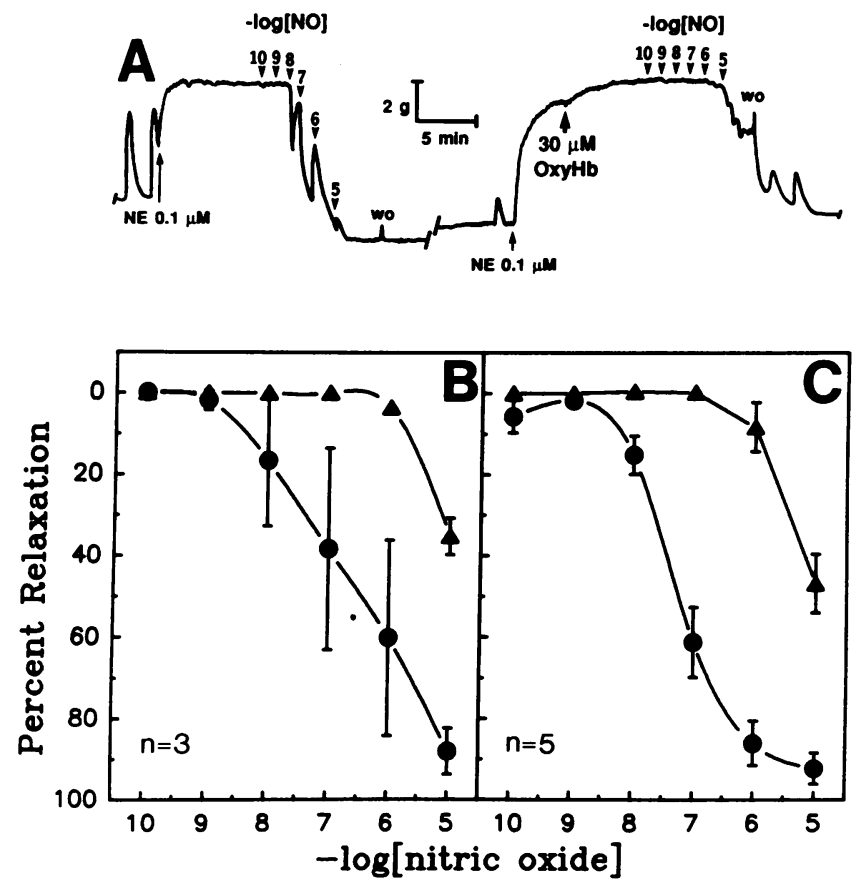

Figure 4. Responses of human and rabbit corpus cavernosum to nitric oxide. Increasing concentrations of nitric oxide were added, in a cumulative fashion, to strips of human $(A$ and $B$, circles) or rabbit $(C$ circles) corpus cavernosum contracted with norepinephrine. After several exchanges of fresh buffer, the protocol was repeated in the absence (time control, not shown) or presence ( $B$ and $C$, triangles) of 30 $\mu \mathrm{M}$ oxyhemoglobin. Time controls exhibited no significant variance in responses for the duration of the experiment.

6, neurogenic relaxation in endothelium denuded corporal strips was greatly attenuated or completely blocked by oxyhemoglobin $(30 \mu \mathrm{M})$, L-NMMA $(0.3 \mathrm{mM})$, hypoxia $\left(\mathrm{Po}_{2}=5-10\right.$ $\mathrm{mmHg})$, or methylene blue $(0.1 \mathrm{mM})$. As with endotheliummediated relaxation, the inhibitory effect of hypoxia was readily reversed when normoxic conditions were restored and the effects of L-NMMA on electrical stimulation were prevented by treatment with $0.3 \mathrm{mM} \mathrm{L}$-arginine (Figs. $5 C$ and 6), but not by equimolar amounts of $\mathrm{D}$-arginine.

\section{Discussion}

Our data suggest that nitric oxide, or a closely related molecule, acts as an endothelium-derived relaxing substance as well as a

Table I. Control Responses to TES

\begin{tabular}{ccr}
\hline & \multicolumn{2}{c}{ Percent of maximal relaxation } \\
\cline { 2 - 3 } $\begin{array}{c}\text { Stimulation } \\
\text { frequency }\end{array}$ & $\begin{array}{c}\text { Human } \\
(n=8)\end{array}$ & $\begin{array}{r}\text { Rabbit } \\
(n=19)\end{array}$ \\
\hline$H z$ & & \\
0.5 & $22.6 \pm 6.9$ & $5.7 \pm 1.0$ \\
1 & $39.1 \pm 7.4$ & $16.0 \pm 2.8$ \\
2 & $49.7 \pm 6.4$ & $36.1 \pm 5.6$ \\
5 & $53.9 \pm 5.5$ & $52.4 \pm 5.9$ \\
15 & $54.0 \pm 4.8$ & $63.3 \pm 5.4$ \\
40 & $53.6 \pm 6.2$ & $68.5 \pm 5.0$ \\
\hline
\end{tabular}

Human and rabbit corpus cavernosum tissues devoid of functional endothelium were subjected to TES in the presence of $0.1 \mu \mathrm{M}$ atropine, $10 \mu \mathrm{M}$ bretylium, and $3 \mu \mathrm{M}$ indomethacin, as described in Fig. 5 and Methods. The values are the means \pm SE. 


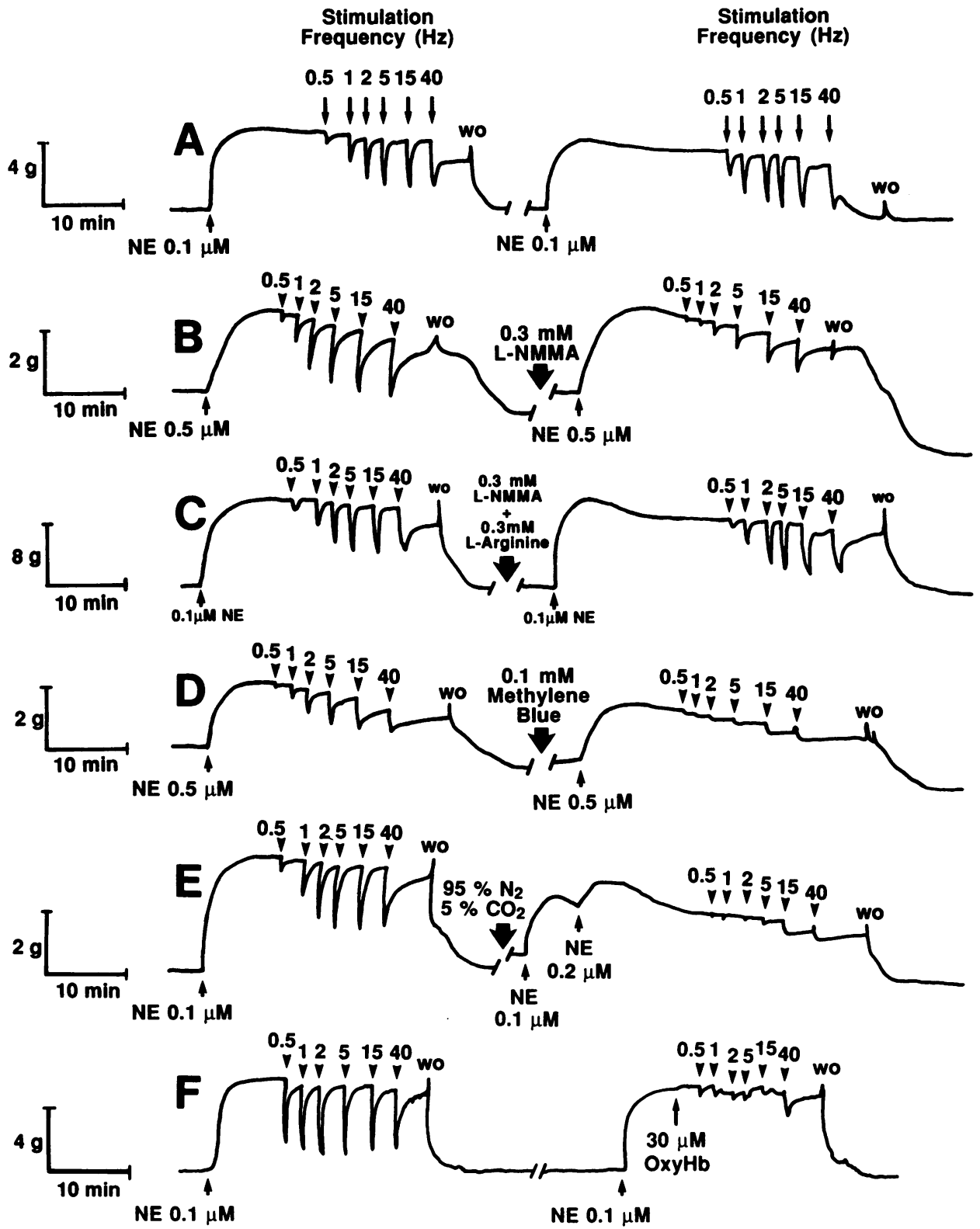

Figure 5. Responses of human corpus cavernosum lacking functional endothelium. Strips of corpora were contracted with norepinephrine $(N E)$ and subjected to electrical stimulation $(A-F)$. Tissues either received no further treatment $(A)$ or were treated with $0.3 \mathrm{mM} \mathrm{L}$ NMMA $(B), 0.3 \mathrm{mM}$ L-NMMA and $0.3 \mathrm{mM}$ L-arginine $(C), 0.1 \mathrm{mM}$ methylene blue $(D), 95 \% \mathrm{~N}_{2}, 5 \%$ $\mathrm{CO}_{2}$ (hypoxic conditions) $(E)$, or 30 $\mu \mathrm{M}$ oxyhemoglobin $(F)$. Electrical stimulations were then repeated as soon as a stable contraction was obtained $(F)$ or after a 20-min incubation $(B-E)$ with the appropriate drug. All protocols were carried out in the presence of $0.1 \mu \mathrm{M}$ atropine, $10 \mu \mathrm{M}$ bretylium, and $3 \mu \mathrm{M}$ indomethacin. See Fig. 6 for summary data. Exchanges of fresh PSS denoted by wo (washout).

neurotransmitter released by NANC inhibitory nerves in penile smooth muscle. Relaxation of corporal smooth muscle to exogenous ACh requires the endothelium because its removal prevents this response (1). Synthesis of endothelium-derived nitric oxide can be inhibited with L-NMMA by competition with endogenous pools of $\mathrm{L}$-arginine, the initial substrate for nitric oxide synthesis (11). The specificity of the effects of $L$ NMMA on acetylcholine-induced relaxation of corporal smooth muscle is confirmed by the inhibition of L-NMMA action by $\mathrm{L}$-arginine, but not its enantiomer, D-arginine, as reported in other studies $(5,6,10,21)$.

Oxyhemoglobin is rapidly oxidized $(<100 \mathrm{~ms})$ by nitric oxide to methemoglobin with concurrent formation of nitrate $(14,22)$. This reaction endows oxyhemoglobin with properties to be an excellent scavenger of the nitric oxide secreted by cells. Because hemoglobin is a large molecule that cannot efficiently cross the plasma membrane, the inhibition of acetylcholine-in- duced relaxation provides further support for a diffusible nitric oxide-like substance being released by the endothelium.

Hypoxia, by a mechanism not fully understood, has also been observed to block the production of endothelium-derived nitric oxide and the accumulation of cyclic cGMP in blood vessels $(2,12)$. As has been reported in rabbit pulmonary artery (12), hypoxia does not alter the relaxatory response to exogenous nitric oxide in corpus cavernosum (unpublished observations), supporting the contention that hypoxia inhibits the synthetic and/or secretory mechanisms of nitric oxide rather than inhibiting its action on target cells. Therefore, the inhibitory effect of hypoxia on acetylcholine-induced relaxation provides additional evidence for the role of nitric oxide in corporal smooth muscle relaxations.

Nitric oxide stimulates soluble guanylate cyclase in smooth muscle, leading to the accumulation of cGMP and smooth muscle relaxation $(10,12,23,24)$. Inhibition of endothelium- 


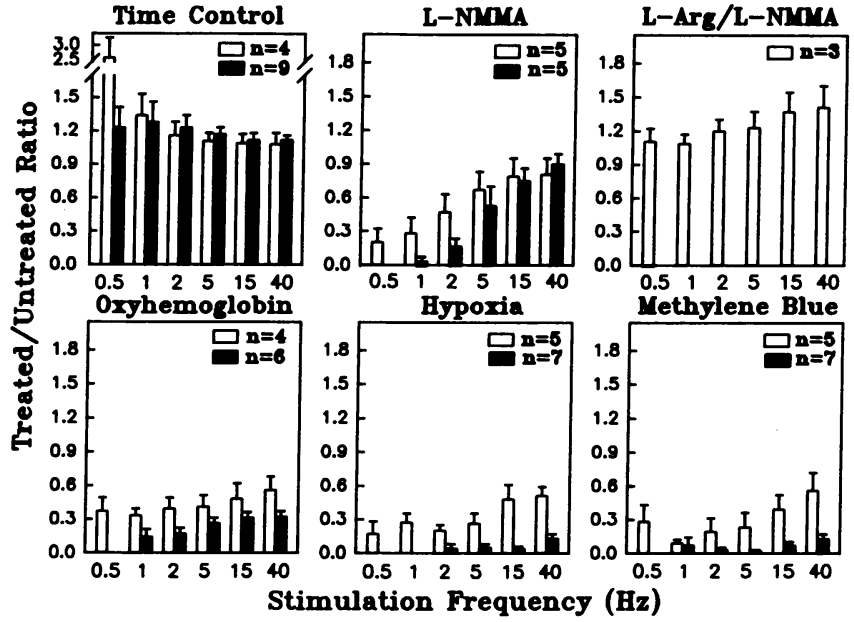

Figure 6. Responses of human (open bars) and rabbit (solid bars) corpus cavernosum lacking functional endothelium. Experimental protocol is identical to that of Fig. 5. For each frequency, the relaxatory responses obtained with the indicated treatments were divided by the responses obtained with no treatment in the same tissue strip. L-NMMA treatment in the presence of L-arginine was performed only in human tissue strips.

mediated relaxation by methylene blue, a guanylate cyclase inhibitor, suggests this relaxatory response is mediated through an increase in cGMP in corporal smooth muscle. Thus, the inhibitory effects of L-NMMA, oxyhemoglobin, hypoxia, and methylene blue on acetylcholine-induced relaxations in both human and rabbit corporal tissues suggest that nitric oxide is released by the endothelium and stimulates CGMP accumulation in corpus cavernosum.

The inhibitory effects of L-NMMA, oxyhemoglobin, and hypoxia on NANC neurogenic relaxation of endotheliumdenuded corpus cavernosum strips strongly suggest that a diffusible nitric oxide-like factor is also released by the penile autonomic nerves. It is possible that NANC nerves release a precursor of nitric oxide that is metabolized in the smooth muscle to NO. However, the recent localization of NO synthase to the autonomic nerves (8) but not the smooth muscle in vascular and nonvascular tissues would strongly suggest that the synthesis of NO occurs directly in the neuron.

The synthesis of nitric oxide or closely related molecules in cells other than the endothelium has been demonstrated in macrophages (25), neutrophils (26), and neuroblastoma cells (27). Additionally, an intercellular messenger with characteristics similar to nitric oxide is synthesized and released in the central nervous system by cerebellar cells (4). Neurogenic relaxation in certain nonvascular smooth muscle tissues, such as the anococcygeus muscle of rat and mouse, has been found to be inhibited by analogues of $\mathrm{L}$-arginine $(5,6)$. A transferable factor, released by nerves in the canine ileocolonic junction and detected by perfusion bioassay experiments, has been reported to have behavior similar to nitric oxide (7). These studies, in combination with our findings in the corpus cavernosum, provide evidence for a nitric oxide-like factor acting as a neurotransmitter in peripheral autonomic nerves and suggest a common mechanism for NANC inhibitory neurotransmission in various organs.
The inhibition of NANC neurogenic relaxation by methylene blue indicates that nerve-derived nitric oxide-like factor may mediate its effects through the same cGMP-dependent mechanism as endothelium-derived nitric oxide. Thus, it would appear that intracellular guanylate cyclase in corporal smooth muscle is the common target for both nerve- and endothelium-mediated inhibitory mechanisms. Stimulation of guanylate cyclase would cause accumulation of cGMP with relaxation of corporal smooth muscle, leading to penile erection.

Diabetes mellitus impairs endothelium-dependent and neurogenic relaxation of penile smooth muscle from diabetic men with impotence but does not alter the responsiveness of the smooth muscle to the nitric oxide-producing vasodilator, nitroprusside (28). In view of the observations reported in the present study, it is possible that diabetes interferes with the nitric oxide pathway which would result in endothelial dysfunction, as well as neuropathy, in the penis. The inability to relax penile smooth muscle would lead to impotence.

\section{Acknowledgments}

This research was supported by grants DK-39080, DK-40025, and DK40487 from the United States Public Health Service.

\section{References}

1. Saenz de Tejada, I., R. Blanco, I. Goldstein, K. Azadzoi, A. de las Morenas, R. J. Krane, and R. A. Cohen. 1988. Cholinergic neurotransmission in human corpus cavernosum. I. Responses of isolated tissue. Am. J. Physiol. 254:H459H467.

2. Furchgott, R. F., and J. V. Zawadski. 1980. The obligatory role of endothelial cells in the relaxation of arterial smooth muscle by acetylcholine. Nature (Lond.). 288:373-376.

3. Ignarro, L. J., P. A. Bush, G. M. Buga, K. S. Wood, J. M. Fukuto and J. Rajfer. 1990. Nitric oxide and cyclic GMP formation upon electrical field stimulation cause relaxation of corpus cavernosum smooth muscle. Biochem. Biophys. Res. Commun. 170:843-850.

4. Garthwaite, J., S. L. Charles, and R. Chess-Williams. 1988. Endotheliumderived relaxing factor release on activation of NMDA receptors suggests role as intercellular messenger in the brain. Nature (Lond.). 336:385-388.

5. Gillespie, J. S., X. Liu, and W. Martin. 1989. The effects of $L$-arginine and $\mathrm{N}^{\mathrm{G}}$-monomethyl L-arginine on the response of the rat anococcygeus muscle to NANC nerve stimulation. Br. J. Pharmacol. 98:1080-1082.

6. Gibson, A., S. Mirzazadeh, A. J. Hobbs, and P. K. Moore. 1990. L-NG. Monomethyl arginine and $\mathrm{L}-\mathrm{N}^{\mathrm{G}}$-nitro arginine inhibit non-adrenergic, non-cholinergic relaxation of the mouse anococcygeus muscle. Br. J. Pharmacol. 99:602606.

7. Bult, H., G. E. Boeckxstaens, P. A. Pelckmans, F. H. Jordaens, Y. M. Van Maercke, and A. G. Herman. 1990. Nitric oxide as an inhibitory non-adrenergic non-cholinergic neurotransmitter. Nature (Lond.). 345:346-347.

8. Bredt, D. S., P. M. Hwang, and S. H. Snyder. 1990. Localization of nitric oxide synthase indicating a neural role for nitric oxide. Nature (Lond.). 347:768770.

9. Palmer, R. M. J., A. G. Ferrige, and S. Moncada. 1987. Nitric oxide release accounts for the biological activity of endothelium-derived relaxing factor. $\mathrm{Na}$ ture (Lond.). 327:524-526.

10. Vane, J. R., E. E. Änggård and R. M. Botting. 1990. Regulatory functions of the vascular endothelium. N. Engl. J. Med. 323:27-36.

11. Palmer, R. M. J., D. S. Ashton, and S. Moncada. 1988. Vascular endothelial cells synthesize nitric oxide from L-arginine. Nature (Lond.). 333:664-666.

12. Johns, R. A., J. M. Linden, and M. J. Peach. 1989. Endothelium-dependent relaxation and cyclic GMP accumulation in rabbit pulmonary artery are selectively impaired by moderate hypoxia. Circ. Res. 65:1508-1515.

13. Gruetter, C. A., P. J. Kadowitz, and L. J. Ignarro. 1981. Methylene blue inhibits coronary arterial relaxation and guanylate cyclase activation by nitroglycerin, sodium nitrite and amyl nitrite. Can. J. Physiol. Pharmacol. 59:150-156.

14. Keilin, D., and E. F. Hartree. 1937. Reaction of nitric oxide with haemoglobin and methaemoglobin. Nature (Lond.). 139:548. 
15. Simons, E. R., P. Hartzband, J. Whitin, and C. Chapman. 1976. Circular dichroism studies of cyanate-induced conformational changes in hemoglobins $A$ and S. Biochemistry. 15:4059-4064.

16. Antonini, E., and M. Brunori. 1971. Hemoglobin and Myoglobin in Their Reactions with Ligands. Elsevier Science Publishing, New York. 18.

17. Saenz de Tejada, I., N. Kim, I. Lagan, R. J. Krane, and I. Goldstein. 1989. Regulation of adrenergic activity in penile corpus cavernosum. J. Urol. 142:1117-1121.

18. Koutts, J., M. A. Howard, and B. G. Firkin. 1974. Factor 8 physiology and pathology in man. Semin. Hematol. 11:115-145.

19. Tesfamariam, B., W. Halpern, and G. Osol. 1985. Effects of perfusion and endothelium on the reactivity of isolated resistance arteries. Blood Vessels. 22:301-305.

20. Mukai, K., J. Rosai, and W. H. C. Burgdorf. 1980. Localization of factor VIII-related antigen in vascular endothelial cells using an immunoperoxidase method. Am. J. Surg. Pathol. 4:273-276.

21. Rees, D. D., R. M. Palmer, H. F. Hodson and S. Moncada. 1989. A specific inhibitor of nitric oxide formation from $\mathrm{L}$-arginine attenuates endothelium-dependent relaxation. Br. J. Pharmacol. 96:418-424.

22. Kelm, M., and J. Schrader. 1990. Control of coronary vascular tone by nitric oxide. Circ. Res. 66:1561-1575.
23. Gruetter, C. A., D. Y. Gruetter, J. E. Lyon, P. J. Kadowitz, and L. J. Ignarro. 1981. Relationship between cyclic guanosine 3':5'-monophosphate formation and relaxation of coronary arterial smooth muscle by glyceryl trinitrate, nitroprusside, nitrite and nitric oxide: effects of methylene blue and methemoglobin. J. Pharmacol. Exp. Ther. 219:181-186.

24. Barnette, M., T. J. Torphy, M. Grous, C. Fine, and J. S. Ormsbee III. 1989. Cyclic GMP: a potential mediator of neurally- and drug-induced relaxation of opossum lower esophageal sphincter. J. Pharmacol. Exp. Ther. 249:524-528.

25. Stuehr, K. J., S. S. Gross, I. Sakuma, R. Levi, and C. F. Nathan. 1989. Activated murine macrophages secrete a metabolite of arginine with the bioactivity of endothelium-derived relaxing factor and the chemical reactivity of nitric oxide. J. Exp. Med. 169:1011-1020.

26. Wright, C. D., A. Mülsch, R. Busse, and H. Osswald. 1989. Generation of nitric oxide by human neutrophils. Biochem. Biophys. Res. Commun. 160:813819.

27. Gorsky, L. D., U. Förstermann, K. Ishii, and F. Murad. 1990. Production of an EDRF-like activity in the cytosol of N1E-1 15 neuroblastoma cells. FASEB (Fed. Am. Soc. Exp. Biol.) J. 4:1494-1500.

28. Saenz de Tejada, I., I. Goldstein, K. Azadzoi, R. J. Krane, R. A. Cohen. 1989. Impaired neurogenic and endothelium-mediated relaxation of penile smooth muscle from diabetic men with impotence. N. Engl. J. Med. 320:10251030 